\title{
A RELEITURA DO CONCEITO DE SOBERANIA E OS PAÍSES IBERO-AMERICANOS: UMA ANÁLISE DO CONCEITO TRADICIONAL DE SOBERANIA COMO POTENCIAL FATOR NA REPRODUÇÃO DOS CUSTOS SOCIAIS NOS PAÍSES IBERO-AMERICANOS
}

InGRID GIACHINI ALTHAUS

Doutoranda em Direito Econômico e Desenvolvimento na PUC/PR (2015). Mestre em Direito Econômico e Socioambiental pela PUC/PR (2012). Professora no curso de Bacharelado em Direito da Fundação de Estudos Sociais do Paraná (FESP). Professora convidada no curso de pós-graduação em Direito Aplicado na Escola da Magistratura do Paraná (Curso de Preparação à Magistratura). Professora convidada na Pós-Graduação Lato Sensu em Gestão Pública da UNICURITIBA, na Pontifícia Universidade Católica do Paraná (PUCPR) e Universidade Positivo. Membro do Grupo de Pesquisa Pró-Polis da Universidade Federal do Paraná (UFPR), coordenado pela Profa. Dra. Angela Cassia Costaldello. Tem experiência na área de Direito Econômico e Ambiental-Urbanístico.

\section{Luís AleXandre Carta Winter}

Doutor em Integração da América Latina pelo USP/PROLAM (2008). Mestre em Integração Latino - Americana pela Universidade Federal de Santa Maria (2001) Graduado em Direito pela Universidade Federal do Paraná (1984). Atualmente é professor adjunto da Pontifícia Universidade Católica do Paraná na graduação (onde foi Coordenador entre 1987 a 1989), e na pós "strito sensu", ex-professor titular e ex-Coordenador "(2005-2010) do Curso de Direito da Faculdade Internacional de Curitiba, professor titular das Faculdades Integradas Curitiba e da FAMEC. Advogado militante deste 1984 e consultor jurídico, atuando principalmente nos seguintes temas e áreas: contratos, integração regional, Mercosul, relações internacionais, direito marítimo, legislação aduaneira, direito internacional econômico e direito internacional. Coordenador do NEADI

\section{Resumo}

O presente artigo parte do pressuposto que se faz necessário um novo conceito de soberania, deixando-se de lado a ideia de poder absoluto nas Naçóes do mundo, vez que se distancia das crescentes demandas propostas pela sociedade globalizada. Analisando-se o conceito de soberania, a partir da Segunda Guerra Mundial, apresentam-se fortemente, dentro das naçôes ibero-americanas, os problemas decorrentes deste olhar tradicional. 
Nessa perspectiva, tomando-se por base o sistema econômico neoliberal, inicialmente estranho à história Ibero-Americana, trabalhou-se com construção desse novo conceito por uma análise econômica do direito, com os fatores paralelamente da eficiência da norma e reprodução dos custos sociais. O significante toma a forma do significado.

\section{Palavras-chave}

Soberania; Comércio e custos; Sistemas econômicos; Ibero-américa.

\section{Abstract}

This article assumes that a new concept of sovereignty is necessary, leaving aside the idea of absolute power of the nations of the world, distancing itself from the increasing demands proposed by the globalized society. Analyzing the concept of sovereignty, from of the Second World War, te problems of this traditional view are highlighted in the Ibero-American nations. From this perspective, taking as a basis the neoliberal economic system, initially foreign to Ibero American history, building work was done with this new concept for an economic analysis of law, the factors parallel efficiency and reproduction of the social costs versus populism. The meaningful takes place of meaning.

\section{Key words}

Sovereignty; Trade and costs; Economic systems; Ibero-America.

\section{Introdução}

Após o fim das duas Grandes Guerras Mundiais, inicia-se um processo de superação do conceito tradicional de soberania, eis que despontam, à época, duas grandes questóes que abalam esta noção: a necessidade de julgar os agentes de Estado pelos crimes atrozes cometidos durante os regimes nazista e fascista, perante a qual as leis estritamente consideradas no âmbito restrito dos Estados-nacionais demonstravam-se insuficientes; e os apátridas (displaced persons) - pessoas desprovidas de nação e, por conseguinte, desprovidas de um Estado nacional que lhes assegurasse seus direitos.

O conceito tradicional de soberania sofre o segundo grande impacto com a concretização do fenômeno da globalização - ou internacionalização - da economia.

A constituição de uma sociedade globalizada, cuja rede interconectada de mercados, comunicação, transporte, informação e cultura, fomenta e promove a constituição de regramentos próprios e de órgãos e instituições de caráter supranacional - Bretton Woods, Banco Mundial, Fundo Monetário Internacional, GATT -, acaba por tornar obsoleta a velha concepção absoluta e inflexível de soberania estatal. 
Isto porque, o mercado global, suas técnicas e regramentos, atuam de maneira transfronteiriça, prevalecendo-se, muitas vezes, sobre o ordenamento jurídico interno dos Estados.

Ademais, busca-se enfocar outro aspecto desta sociedade globalizada: a reprodução dos custos sociais nos países ibero-americanos. Os problemas sociais devem ser vistos como uma diferente faceta da mesma crise, que é, em grande parte, uma crise de percepção, decorrente do fato de que a maioria possui uma visão de mundo obsoleta, uma percepção da realidade inadequada para lidar com o mundo superpovoado e globalmente interligado.

Delineia-se assim o objeto do presente artigo, analisar o conceito tradicional de soberania de modo a demonstrar a necessidade de se fazer uma releitura desta concepção, adequando-a ao fenômeno da integração econômica internacional, bem como à necessidade de eficiência econômica nas normas dos países ibero-americanos, eis que, conforme se buscará demonstrar, as normas prescindem proporcionar o desenvolvimento dos países - é uma obrigação que não pode mais ser atribuída apenas a um Estado determinado, mas à humanidade como um todo.

Assim, busca-se demonstrar que uma consciência social universal que emerge no século XX, e se arraiga no século XXI, e os consequentes regramentos econômicos que dela decorrem, têm o condão de por em cheque o conceito tradicional de soberania e, além disso, representam um limite ao próprio crescimento econômico desordenado dos países ibero-americanos.

\section{O Sistema Econômico Neoliberal}

O sistema econômico capitalista neoliberal desenvolvido e fortalecido na modernidade sustentou-se sobre a ideia de um mercado autossustentável e auto-regulável. A "mão invisível" do mercado, conforme termo introduzido por Adam Smith, pairou sobre a economia por muito tempo como um dogma.

Desta maneira a expansão do capital não tardou a atingir proporçóes globais, acelerando a denominada globalização (ou internacionalização) da economia, caracterizada essencialmente pelo comércio internacional. Na perspectiva de Noam Chomsky (1999, p. 12) essa nova economia global apresenta duas consequências importantes:

Em primeiro lugar, ela estende o modelo do Terceiro Mundo a países industrializados. No Terceiro Mundo, a sociedade divide-se em dois segmentos - um de extrema riqueza e privilégio, e outro de imensa miséria e desespero, formado por pessoas inúteis, dispensáveis.

Tal divisão é acentuada pelas políticas ditadas pelo Ocidente. Ele impôe um sistema neoliberal de 'livre mercado', que canaliza os recursos 
aos ricos e investidores estrangeiros, afirmando que algo irá resultar dali, como num passe de mágica, logo depois da chegada do Messias.

$[\ldots]$

A segunda consequência, também importante, tem a ver com estruturas governamentais. As estruturas de governo tenderam à coalizão, ao longo da história, em torno de outras formas de poder - em tempos modernos, basicamente em torno do poder econômico. Portanto, onde existem economias nacionais existem Estados nacionais. Agora temos uma economia internacional e estamos avançando rumo a um Estado internacional - o que significa, por fim, um executivo internacional. (CHOMSKY, 1999, p. 33)

Citando a imprensa econômica, estamos criando uma "nova era imperial" com um "governo mundial de facto". Ele tem suas próprias instituiçôes - como o Fundo Monetário Internacional (FMI) e o Banco Mundial, estruturas comerciais como o Nafta e o Gatt [o Acordo Norte-Americano de Livre Comércio e o Acordo Geral de Tarifas e Comércio (...)], encontros executivos como o G-7 [os sete países industriais mais ricos - EUA, Canadá, Japão, Alemanha, Grã-Bretanha, França e Itália - que se reúnem regularmente para discutir políticas econômicas] e a burocracia da Comunidade Europeia.

$\mathrm{Na}$ medida em que o neoliberalismo se espraia pelo globo terrestre, impondo políticas econômicas que respondem basicamente aos anseios do capital (corporaçóes transnacionais, bancos internacionais, órgãos econômicos supranacionais), demonstra-se acertada a afirmação realizada por Milton Santos, no sentido de que a "globalização é, de certa forma, o ápice do processo de internacionalização do mundo capitalista.” (2000, p. 23)

No entanto, longe de se tratar de uma questão meramente econômica, centralizada na interdependência entre os países decorrente desta rede econômica global, a globalização envolve uma integração entre os Estados que supera este viés exclusivamente econômico. ${ }^{1}$

Neste sentido, verifica-se que tal integração abarca também, e principalmente, o campo político, utilizando-se das palavras de Luís Alexandre Carta Winter e Marcos Wachowicz (2008, p. 875), o "Estado deixa de ser dono de algumas das suas políticas (...)

1 O fenômeno da globalização não poderia se resumir a um aspecto exclusivamente econômico (avançando sobre a política), eis que conforme salientado por Juan Ramón Capella não há uma separação estanque e absoluta entre Estado e Mercado. Neste sentido o autor afirma que: “... a separação absoluta entre Estado e Mercado, que é outro dos dogmas da modernidade, pode ser posta razoavelmente em questâo, dado que algumas das condiçôes de funcionamento do que costumamos chamar 'mercado' não são meramente econômicas, mas políticas, ou dado que a determinação das relações de intercâmbio mercantil de bens é, em parte, função política (por exemplo, a determinação do nível dos salários, a viabilidade empresarial, os custos empresariais externalizáveis, etc.), pode inferir-se que o 'mercado' só pode ser considerado como autônomo, fazendo abstração de tais componentes 'meta-mercantis'” (CAPELLA, Juan Ramón. Os Cidadáos Servos. Tradução de Lédio Rosa de Andrade e Têmis Correia Soares. Porto Alegre: Sergio Antonio Fabris, 1998, p. 118). 
perde a jurisdição sobre certas matérias, é obrigado a harmonizar a sua legislação com a dos restantes Estados, partes no fenômeno de integração (...) muitas vezes, sem o seu consentimento".

Isso porque, o fenômeno de integraçáo internacional acaba por sobrepor um sistema jurídico a outro, vinculando os seus sujeitos duplamente.

De tal forma, o Estado nacional tornou-se obsoleto para a resolução de inúmeros conflitos decorrentes do processo de globalização, eis que estes, muitas vezes, envolvem questôes transfronteiriças, de modo que se buscou fortalecer as normas internacionais.

Com esse intuito, após a Segunda Guerra Mundial, teve origem o sistema de Bretton Woods, o Fundo Monetário Internacional, Banco Mundial e o Acordo Geral sobre Tarifas e Comércio (GATT).

As instituiçóes de Bretton Woods fizeram uma nova leitura do Direito Internacional Público, conforme preconiza César Augusto Silva, na sua obra "O direito econômico na perspectiva da globalização" (2003, p. 33), o qual "pautava-se por uma ideologia europeia, visto que regulava as relaçóes entre Estados civilizados, entendidos assim os Estados europeus, introduziu critérios que aplicavam-se também aos antigos países coloniais.”

Ademais, consagrou-se "o princípio da autodeterminação dos povos e o da justiça e progresso social para todos os países da nova comunidade mundial” (SILVA, 2003, p. 33), criando-se, por consequência, o Banco Mundial e o Fundo Monetário Internacional, os quais, teoricamente, visam garantir a concretização de tais princípios.

No avanço do direito internacional, com vistas à integração econômica, o GATT fixou um conjunto de normas e um meio multilateral para o comércio de serviços, concomitantemente com a necessidade dos Estados preservarem as condiçóes regulatórias de seus mercados internos, agregando-se, por fim, vários Estados-membros. (SILVA, 2003, p. 33)

Pode-se inferir, portanto, que a integração econômica entre os Estados, bem como o fortalecimento das normas internacionais, decorrentes da necessidade de regulamentação das práticas comerciais, acabou por minar o conceito tradicional de soberania, eis que (CAPELA, 1998, p. 119):

[...] se no âmbito econômico - para começar com este - os Estados, como questáo de fato, se inclinam ante o poder de decisão coletiva das empresas multinacionais e ante as decisóes e condicionamentos, em muitas ocasióes de caráter diretamente político, de instituiçôes tais como o Banco Mundial e o Fundo Monetário Internacional, então, há de reconhecer-se claramente que o conceito de soberania é, nesse âmbito, uma convenção inútil ou, pior, mascaradora da realidade.

Desta forma, faz-se necessário realizar uma breve análise acerca do conceito tradicional de soberania a fim de se demonstrar as razóes pelas quais se sustenta a impossibilidade 
de coexistência deste conceito - sob um viés absoluto e inflexível - com o sistema econômico global e seus custos sociais, na perseguição do bem-estar social, a exemplo dos países ibero-americanos.

Nos países ibero-americanos encontramos inúmeras situaçóes, que se destacam no diz respeito aos demais países do mundo, para explicitar essa tese, como é o caso da Argentina, onde se encontram normas econômicas versus padrão ideológico.

As suas normas são invariavelmente eficientes para implantar um padrão ideológico, mas não são eficientes num padrão de desenvolvimento mundial, pois provocam uma mudança de comportamento na economia de mercado, de dentro para fora, as quais postas e analisadas num contexto global se mostram inadequadas para o equilíbrio econômico dos demais países, que caminham para o desenvolvimento.

Sem formos um pouco mais além, no entanto, é de constatar que as normas políticas implantadas na Argentina muito bem exteriorizam essa questão, pois agravaram e só fazem aumentar ainda mais drasticamente sua crise financeira, que, por consequente, se estende para os demais países interligados a esta economia.

No caso do Brasil, comparativamente, é de se verificar que as suas vendas externas para o país vizinho, em julho de 2014 , foram um terço menores, que no mesmo mês do ano de 2013, ou seja, as suas exportaçóes sofreram uma drástica queda com reflexos espraiados por todo o mercado econômico.

\section{Uma Releitura do Conceito Tradicional de Soberania}

O surgimento da concepção de soberania está atrelado ao nascimento do Estado Moderno e remonta à construção teórica realizada essencialmente por Jean Bodin, em 1576, com o desenvolvimento da obra "Les Six Livres de la République". Nesta obra, Bodin define a República como "o justo governo de muitas famílias, e do que lhes é comum, com poder soberano" ${ }^{2}$, de modo a inserir substancialmente a soberania na definiçáo de República. $^{3}$

A passagem da Idade Média para a Idade Moderna é marcada, portanto, pelos Tratados de Paz de Vestfália que consagraram o "reconhecimento oficial da ideia de uma sociedade internacional integrada por Estados iguais e soberanos.” (BOSON, 1994, p.162)

2 Tradução livre. Texto original: "República es un recto gobierno de varias familias, y de lo que les es común, con poder soberano” (BODIN, Jean. Los seis libros de la república. Tradução de Pedro Bravo Gala. 3 ed. Madrid: Tecnos, 1997, p. 09).

3 Conforme os ensinamentos de Dalmo de Abreu Dallari “a expressão 'República' equivale ao moderno significado de Estado” (DALLARI, Dalmo de Abreu. Elementos de teoria geral do Estado. 20. ed. São Paulo: Saraiva, 1998, p. 77). 
Em sua gênese a soberania constituiu-se, portanto, como um poder absoluto e perpétuo, componente fundamental do Estado, cuja existência passa a depender desta noção. Norberto Bobbio explica em que consistiriam os dois atributos da soberania - absoluto e perpétuo - na perspectiva de Jean Bodin:

O significado de 'perpetuidade' é óbvio, embora não seja claro onde se possa traçar a linha de demarcaçáo entre um poder perpétuo e outro não -perpétuo. Por 'caráter absoluto' se entende que o poder soberano deve ser 'legibus solutus'. Quer dizer: não deve precisar obedecer às leis, isto é, às leis positivas, promulgadas pelos seus predecessores e por ele próprio. (BOBBIO, 1997, p. 96)

O Estado Moderno absorve a concepção de soberania que passa a ser tratada pelos mais diversos filósofos e teóricos do Estado e do Direito. Thomas Hobbes, outro grande filósofo político da Idade Moderna, em consonância com a teoria desenvolvida por Bodin, defende, de maneira ainda menos flexível, o caráter absoluto e indivisível da soberania. (BOBBIO, 1997, p. 96).

No entanto, em Hobbes, a soberania torna-se impessoal, de modo que se transmuda em uma soberania estatal. Já teóricos como John Locke e Jean-Jacques Rousseau transferem a titularidade da soberania para o povo.

Esses teóricos que defendem a doutrina da soberania popular ancoram-se no princípio democrático, de maneira que, conforme sintetizado no pensamento de Rousseau: "se o Estado é composto por de dez mil cidadãos, cada um terá a décima milésima parte da autoridade soberana." (BOBBIO, 1997, p. 96)

Desde a Revoluçáo Francesa, em 1789, solidificou-se e prevaleceu a doutrina democrática segundo a qual a soberania é impessoal, sendo que a titularidade passou do indivíduo à Nação, o que resta evidenciado por meio da leitura do artigo $3^{\circ}$ da Declaraçáo dos Direitos do Homem de 1789: "o princípio de toda a soberania reside essencialmente na Nação e que nenhuma corporação, nenhum indivíduo pode exercer autoridade que dela não emane expressamente."

$\mathrm{Na}$ atualidade, parece pacífico o entendimento de que a soberania pertence ao Estado, bem como que perdeu o seu caráter absoluto, ilimitado, infinito, conforme se observa do conceito bosquejado por Jellinek, a saber: "capacidade do Estado a uma autovinculação e autodeterminação jurídica exclusiva.” (DALLARI, 1998, p. 82-83)

Miguel Reale insere um conteúdo moral no conceito ao afirmar que a soberania caracteriza-se pelo "poder de organizar-se juridicamente e de fazer valer dentro de seu território a universalidade de suas decisôes, nos limites dos fins éticos de conveniência.” (REALE, 1960, p.127) 
No entanto, é de acentuar que a soberania divide-se, ainda, em soberania interna e externa. A soberania interna presta-se a justificar a atuação governamental no âmbito territorial interno de cada Estado. Já a soberania externa confunde-se com a independência de cada Estado, no campo do direito internacional, ou seja, garante a liberdade de atuaçáo perante os demais membros da comunidade internacional. (ACCIOLY, 2000, p. 105)

A este propósito Hildebrando Accioly detalha as competências estatais que representariam expressóes da soberania interna e externa, da seguinte maneira:

A soberania interna compreende os direitos: a) de organização política, ou seja, o de escolher a forma de governo, adotar uma constituição política, estabelecer, enfim, a organização política própria e modificá-la à vontade, contanto que não sejam ofendidos os direitos de outros Estados; b) de legislação, ou seja, o de formular as próprias leis e aplicá-las a nacionais e estrangeiros, dentro, naturalmente, de certos limites; e) de jurisdição, ou seja, o de submeter à ação dos próprios tribunais as pessoas e coisas que se achem no seu território, bem como o de estabelecer a sua organização judiciária; d) de domínio - em virtude do qual o Estado possui uma espécie de domínio eminente sobre o seu próprio território. A soberania externa compreende vários direitos, entre os quais se salientam: o de ajustar tratados ou convençôes, o de legação ou de representação, o de fazer a guerra e a paz, o de igualdade e o de respeito mútuo. (ACCIOLY, 2000, p. 105)

A crise pela qual passa a soberania externa na contemporaneidade deve-se principalmente à dificuldade de harmonização deste conceito com a ordem internacional, na medida em que foi minado pela globalização, pela constituição de órgãos econômicos e entidades supranacionais que espraiam seus efeitos sobre os países internamente, bem como vem cada vez mais sendo flexibilizado pelo movimento de internacionalização dos direitos humanos, direitos em que esta o bem-estar social.

Embora a soberania, por meio do princípio da não-intervenção e da autodeterminação dos povos, tenha sido referendada nos mais diversos diplomas legais de direito internacional, tal garantia entra em choque até com a própria atuação nas práticas de mercado dos Estados, pois indiretamente os reflexos dos custos sociais ocasionados pelas normas econômicas postas são suportadas por todas as pessoas do globo.

Desse modo, a noção de soberania é atacada também pelo mercado global. Na era da globalização, parece estranho querer-se afirmar de maneira tão veemente a soberania externa dos Estados frente às políticas econômicas dos Estados, quando as práticas de mercado atingem de maneira indistinta, e muitas vezes destrutiva, todas as naçóes do globo, sem limitaçóes espaciais.

A expressão Suprema potestas non regotiones deixa de ser verdadeira em prol dos atributos da soberania. Cumpre-se observar que este assunto, já é, há muito, superado entre 
as potencias europeias, mais ainda tem o condão de causar celeuma dentro da Ibero-América em geral e do Brasil em particular.

\section{Conclusões}

A fissura está posta. O mercado timidamente rompeu com o conceito tradicional de soberania de Estado.

No mundo contemporâneo, a crise da soberania externa deve-se, em muito, à dificuldade de harmonização do seu conceito com a ordem internacional, na medida em que foi minado pela globalização, pela constituição de órgãos econômicos e entidades supranacionais que espraiam seus efeitos sobre os países internamente, bem como vem cada vez mais sendo flexibilizado pelo movimento de internacionalização dos direitos humanos.

Conforme tratamos nesse artigo, para se definir a questão da soberania, na atualidade, impende questionar a respeito se há ou não sobreposição da ordem jurídica internacional em relação ao ordenamento interno.

Nessa linha de raciocínio, é de acrescer que o desenvolvimento econômico global não pode olvidar os custos sociais mundiais como fator de ingerência nos Estados (e, portanto, de flexibilização da soberania) e como fator limitador do desenvolvimento - em sua concepção estrita de crescimento econômico.

O estudo da reproduçáo dos custos sociais nas normas aparentemente eficientes dos países compete à humanidade como um todo, não podendo ser visto de forma setorizada, mas apenas globalmente, através de uma visão holística.

Nas palavras de WALD (2005, p. 05), "precisamos de uma economia de mercado inspirada com direito, e um direito que considere as regras de mercado", posto que "se houver um mercado sem direito, teremos uma selva selvagem”.

Com base nesta assertiva, podemos afirmar que um mercado sem regras é um mercado de bárbaros. Sem regras não há segurança nas açóes; prevalece apenas o interesse individual e o desenvolvimento da sociedade e da economia se apresentaria em um panorama apenas distante, se é que possível.

O direito, em relação com a economia, tem o papel de garantidor. Especialmente quando determina a alocação dos direitos de propriedade e de segurança na efetividade das transaçóes, minimizando o impacto dos custos sobre a eficiência econômica. Ao direito também é conferida a função distributiva, especialmente no que tange à renda e riscos aos agentes econômicos. É o efetivador da cooperação social.

A esse passo, temos que o direito é indutor das condutas em todo o sistema econômico. Partindo do pressuposto que as pessoas reagem a estímulos, positivos ou negativos, 
o direito enquanto conjunto de regras serve de guia a induz o indivíduo à prática de comportamentos tidos como ideais pela sociedade.

Logo, é através deste ordenamento que teremos um mercado saudável e equilibrado. Por meio de um regramento seguro, instalado em muito devido à vontade política e embasamento cultural desta sociedade, teremos as condiçóes de equilíbrio entre economia, direito e mercados. Criar-se-ão, assim, condiçôes ideais para a instalação de fato de uma economia de mercado, atraindo investimentos e gerando, de fato, o desenvolvimento econômico.

Com esse olhar, é imperiosa uma nova leitura do conceito de soberania, e, de tal maneira, uma nova leitura da reprodução dos custos sociais nas normas econômicas dos países, de dentro para fora, a maneira que seja um limitador nos órgáos internacionais econômicos.

No cenário atual dos países ibero-americanos tem-se um largo campo de estudo a respeito dessa temática, de modo que se espera que esse artigo seja um convite a seus leitores para tanto.

Partindo-se da ideia de que a operacionalidade de normas economicamente eficientes no Estado Soberano integram os elementos de reprodução dos custos sociais e econômicos na sociedade mundial, seria interessante refletir sobre as consequências dos Estados que operam de forma a desconsiderar a interconexão entre a eficiência da norma na economia de mercado mundial e os custos sociais no Estado de Direito, bem como os fatores históricos e culturais que lhes são constitutivos.

Aqui, a maioria das estratégias econômicas propostas pelos Estados Ibero-Americanos, sob o argumento da preponderância da soberania internacional, consideram apenas a eficiência econômica da norma na prática de mercado, mas, verdadeiramente não as associa ao custo social, pelo contrário, as trata como fossem duas coisas separadas, razão pela qual há enormes resistências populistas.

Para o viés populista majoritário, o significante toma a forma do significado. A ameaça da eficiência da norma na economia de mercado representa um ataque mais do que a norma em si, ao social. A experiência chilena mereceria apurada reflexão, sob este prisma, pois, ao que parece, passa a ser uma importante exceção, ao associar a eficiência econômica e custos sociais.

Um mercado absolutamente livre é, por via de consequência, um mercado monopolista, onde a concorrência é substituída por acordos, pela dominação exclusiva do poder econômico.

A atuação do Estado não deve, contudo, ser restritiva da atividade econômica ou refrear os impulsos daqueles que por mérito e competência conquistam o mercado, como é o caso da concorrência no mercado imobiliário. 
O Estado deve privilegiar a competência, garantindo ao menos a possibilidade de entrada e competição daquele que, por razóes de capacidade financeira, não pode atuar da mesma forma que as grandes corporaçóes, como o próprio Estado, no caso do mercado imobiliário.

As políticas públicas precisam autorizar uma concorrência saudável de pessoas, preços e qualidade; encoraja a atividade econômica, possibilitando que estes se desenvolvam frente ao Poder Público e aos demais, por meio de competência e inovaçóes tecnológicas; e, especialmente, estimula o desenvolvimento dos países de forma mais igualitária e justa.

\section{Referências}

ACCIOLY, Hildebrando. Manual de direito internacional público. 14. ed. São Paulo: Saraiva, 2000.

BARRETTO. Vicente de Paulo. O Fetiche dos Direitos Humanos e outros temas. Rio de Janeiro: Lumen Juris. 2010.

BECK, Ulrich. La Sociedad del riesgo global. Traducción de Jesús Alborés Rey. Madrid: siglo veintiuno de espańa editores. 2002.

BOBBIO, Norberto. A teoria das formas de governo. Tradução de Sérgio Bath. 10. ed. Brasília: UNB, 1997.

BODIN, Jean. Los seis libros de la república. Tradução de Pedro Bravo Gala. 3 ed. Madrid: Tecnos, 1997.

BOFF, Leonardo. Os limites do Capital sáo os limites da Terra. Agência Carta Maior -Econômica. São Paulo, 2009.

BONAVIDES, Paulo. Ciência Política. 10. ed. São Paulo: Malheiros, 1998.

BOSON, Gerson de Brito Mello. Direito internacional público: o Estado em direito das gentes. Belo Horizonte: Del Rey, 1994.

CAMARGO, Ana Luiza de Brasil. Desenvolvimento sustentável: dimensóes e desafios. São Paulo: Papirus, 2003.

CAPELLA, Juan Ramón. Os Cidadáos Servos. Tradução de Lédio Rosa de Andrade e Têmis Correia Soares. Porto Alegre: Sergio Antonio Fabris, 1998.

CAPRA, Fritjof. A teia da vida: uma nova compreensão científica dos seres vivos. 6 ed. Cutrix, 2001.

CHOMSKY, Noam. A Minoria Próspera e a Multidáo Inquieta. 2. ed. Tradução de Mary Grace Fighiera Perpétuo. Brasília: UNB, 1999. 
CINTRA. Marcos Antonio Macedo. A agenda de negociaçóes internacionais em serviços financeiros. Economia Política Internacional: Análise estratégica. Campinas, número 01, páginas 15 a 20, abril/junho de 2004. Disponível em: <http://www.eco. unicamp.br/asp-scripts/boletim_ceri/boletim/boletim1/VersaoIntegral.pdf>. Acesso em: 14 fev. 2011.

DALLARI, Dalmo de Abreu. Elementos de teoria geral do Estado. 20. ed. São Paulo: Saraiva, 1998.

FERRAJOLI, Luigi. A soberania no mundo moderno. São Paulo: Martins Fontes, 2003.

FLORES, Joaquín Herrera. Direitos Humanos, Interculturalidade e Racionalidade. In: WOLKMER, Antonio Carlos. Direitos Humanos e Filosofia na América Latina. Rio de Janeiro: Lúmen Júris, 2004.

FREITAS, Mariana Almeida Passos de. O desenvolvimento sustentável dentro de uma perspectiva de Direitos Humanos e Direito Ambiental Internacional. In: PIOVESAN, Flávia. Direitos Humanos. Curitiba, Juruá, 2006.

GABARDO, Emerson. Interesse público e subsidiariedade: o Estado e a sociedade civil para além do bem e do mal. Belo Horizonte: Fórum, 2009.

GOMES, Luiz; MAZZUOLI, Valerio de Oliveira. Direito supraconstitucional:do absolutismo ao estado constitucional e humanista de direito. São Paulo: Revista dos Tribunais, 2010.

HABERMAS, Jürgen. A Inclusáo do Outro: estudos de teoria política. Tradução de George Sperber e Paulo Astor Soethe. São Paulo: Loyola, 2002.

KELSEN, Hans. Teoria Geral do Direito e do Estado. 3. ed. São Paulo: Martins Fontes, 1998.

LEFF, Enrique. Saber ambiental: sustentabilidade, racionalidade, complexidade, poder. Petrópolis: Vozes, 2001.

MAGALHÃES, José Luiz Quadros de. Direito constitucional. Tomo II. Belo Horizonte: Mandamentos, 2002.

MARÉS. Carlos Frederico. Direitos Invisíveis. In: OLIVEIRA, Francisco de. PAOLI, Maria Célia (org.). Os sentidos da democracia: políticas do dissenso e hegemonia global. Nedic: Petropólis, Vozes: Brasília, 1999.

NUSDEO, Fábio. Curso de Economia: Introdução do Direito Econômico. São Paulo, RT, 1997. p. 341 e 395. Apud GABARDO, Emerson. Interesse público e subsidiariedade: o Estado e a sociedade civil para além do bem e do mal. Belo Horizonte: Fórum, 2009.

REALE, Miguel. Teoria do direito e do Estado. 2. ed. São Paulo: Martins, 1960. 
ROUSSEAU, Jean Jacques. Do contrato social. Princípios do direito político. São Paulo: Revista dos Tribunais, 2003.

SANTOS, Milton. Por uma outra globalização. 4. ed. Rio de Janeiro : Record, 2000.

SEN, Amartya. Desenvolvimento como liberdade. Trad. Laura Teixeira Motta. São Paulo: Companhia das Letras, 2008.

SILVA. César Augusto. O direito econômico na perspectiva da globalização. Rio de Janeiro : Renovar, 2000.

SIRVINSKAS, Luís Paulo. Manual de Direito Ambiental. 7 ed. rev. atual e ampl. São Paulo: Saraiva, 2009.

SUNKEL, Osvaldo. A sustentabilidade do desenvolvimento atual. In: ARBIX, Glauco, Mauro Zilbovicius e Ricardo Abramovay (orgs.) Razôes e ficções do desenvolvimento. São Paulo: Editora Unesp \& Edusp, 2001. p. 261. Citado por VEIGA, José Eli da. Desenvolvimento Sustentável: o desafio do século XXI. 3 ed. Rio de Janeiro: Garamond, 2008.

TRINDADE, Antônio Augusto Cançado. Direitos humanos e meio ambiente: paralelo dos sistemas de proteçáo internacional. Porto Alegre: Sergio Antonio Fabris, 1993.

WINTER, Luis Alexandre Carta. Wachowicz, Marcos. Estado: Construçáo de uma identidade. Congresso Nacional do CONPEDI (16.: 2007: Belo Horizonte, MG) Anais do XVI Congresso Nacional do CONPEDI [Recurso eletrônico]. - Florianópolis : Fundação Boiteux, 2008. 